\section{Interplay of aberrations and visual parameters in pseudophakic eyes}

MA Nanavaty and DJ Spalton

\section{Eye (2008) 22, 1453-1455; doi:10.1038/eye.2008.303}

Technological advances in wavefront sensing and adaptive optics are revolutionising the way we think of and treat refractive errors. This has made cataract surgery evolve from a sightsaving procedure to a refractive procedure where quality of vision and optical outcome are of crucial importance and visual acuity alone cannot be considered the sole criterion of surgical success. As a result, it is becoming a necessity for the practicing ophthalmologist to have a working understanding of a barrage of new concepts and theories relating to these advances.

The assessment of visual and optical quality of an eye can be divided into two broad groups: those which measure purely optical function and those which in addition require retinal and cortical processing. Wavefront analysis, point spread function (PSF), and modulation transfer function (MTF) provide parameters of the quality of an optical system, whereas contrast sensitivity also incorporates retinal and cortical processing. Wavefront analysis isolates the effect of different aberrations and analyses the contributions of individual aberrations on optical quality. PSF is the intensity distribution of light from a point source projected on to the retina and indicates the extent of blurring of the retinal image. It contains information about the MTF in all meridians, this is the ratio of image contrast to object contrast as a function of spatial frequency and can be derived by the Fourier transformation of the PSF. The MTF of the human eye is dependent on pupillary diameter, ${ }^{1}$ as larger pupillary diameters include more aberration, particularly spherical aberration. It can be measured either by directly imaging the PSF on the retinal surface ${ }^{2}$ or by calculating the PSF from wavefront or ray tracing. ${ }^{3}$ Each method gives a different result, as directly imaging the PSF also includes contributions from diffraction, scatter, and phase shift. The
MTF can be graphically represented as the object to image contrast at various spatial frequencies. Thirty cycles/degree represents approximately 6/6 acuity, whereas 3-6 cycles/degree is more important for daily living requirements. The MTF can also be quantified by the Strehl ratio, which compare the MTF to that of a best possible diffraction-limited system.

Several studies have reported that optical quality of an eye decreases with age. ${ }^{4-7}$

Although a significant part of the degradation is due to scattering from the human lens, ${ }^{8}$ some is caused by the increase in spherical aberration of the crystalline lens towards more positive values that add to the positive corneal spherical aberration. ${ }^{5}$ Conventional spherical intraocular lenses (IOLs) degrade image quality by failing to correct the corneal spherical aberration, and decreasing spherical aberration by using aspheric IOLs has been shown to improve retinal image quality and mesopic contrast sensitivity. ${ }^{9-17}$ Today many companies manufacture aspheric IOLs of different asphericity. For example, the Alcon AcrySof IQ corrects $0.17 \mu \mathrm{m}$ leaving the residual spherical aberration of approximately $0.1 \mu \mathrm{m}$, the AMO Tecnis correct $0.27 \mu \mathrm{m}$ leaving virtually zero spherical aberration, and the Bausch and Lomb Akreos AO is neutral to corneal spherical aberration leaving residual spherical aberration equal to corneal spherical aberration. It still remains to be seen whether varying the amount of spherical aberration correction will cause significant differences in mesopic and photopic contrast sensitivity.

The effects of decentration and tilt on these newer aspheric IOLs are important. Several theoretical and computational studies predict that tilt and decentration are more deleterious in aspheric than spheric surfaces, ${ }^{18,19}$ and in a study, Holladay et $a l^{20}$ showed that decentration $>0.4 \mathrm{~mm}$ and tilt $>7$ degrees would cancel the optical benefit of correcting spherical aberration. It is difficult to measure the exact
Department of Ophthalmology, St Thomas' Hospital, London, UK

Correspondence: MA Nanavaty, Department of Ophthalmology, St Thomas' Hospital, Lambeth Palace Road, London, London, England SE1 7EH, UK Tel: + 00442071888650 ; Fax: + 00442071884318 E-mail: mayank_nanavaty@ hotmail.com 
amount of decentration and tilt in an eye relative to the visual and the optical axis. Studies typically measure IOL decentration relative to the centre of the pupil, but the visual axis is usually offset nasally from the centre of the pupil (the angle kappa, normally about $4^{\circ}$ ), and although the IOL may be centred in the bag, the bag may not be completely centred on the visual axis.

This issue presents a study by Kim et al, ${ }^{21}$ comparing higher order aberrations in eyes with the Tecnis Z9003 (an aspheric) and AcrySof SA60AT (a spheric) IOL, showing a difference of $0.55 \mu \mathrm{m}$ for total ocular spherical measurements at $6 \mathrm{~mm}$ pupil size. In comparison with the older models of same IOL, Zeng et $a l^{22}$ found a difference of $0.15 \mu \mathrm{m}$ in spherical aberration at 3 months for total eye measurement at $6 \mathrm{~mm}$ pupil size, whereas Caprossi et $a l^{23}$ found a difference of $0.57 \mu \mathrm{m} 2$ months postoperatively at $5 \mathrm{~mm}$ pupil size.

Kim et $a l^{21}$ report significantly more vertical coma $\left(\mathrm{Z}_{3}^{-1}\right)$ with the spherical AcrySof SA60AT which is interesting. We compared the wavefront aberrations of the AcrySof SN60WF with AcrySof SN60AT and found significantly more vertical coma $\left(Z_{3}^{-1}\right)$ for total and internal aberration at a $5 \mathrm{~mm}$ pupil diameter with spheric IOL. ${ }^{24}$ This suggest that aspheric IOLs reduces the vertical coma significantly. Bellucci et $a l_{,}^{25}$ also found reduced ocular vertical coma with the Tecnis. In the Roman alphabet, vertical elements predominate, and the recognition of these are important for reading ability. ${ }^{26}$ Vertical coma in combination with spherical aberration would produce multifocality of the retinal image along the vertical axis and this may improve near visual acuity of the English letters. In our study, we found a small but significant difference in distance corrected near LogMAR visual acuity with the spheric IOL (equating to one line more on LogMAR chart). ${ }^{24}$ Further studies correlating distance corrected near vision with bilateral spheric or aspheric implantation are required.

Hence, the evolving interest in the interplay of different aberrations in a pseudophakic eye is fascinating but critical assessment of patient benefits are still required. Aspheric IOLs undoubtedly gives a small improvement in mesopic contrast sensitivity but there is no change in visual acuity and a patient who has had an aspheric IOL in one eye and spheric in the other cannot usually tell a difference between the two eyes. Spherical aberration is pupil size dependent and most patients with senile cataract have relatively smaller pupil diameter from senile miosis, which may explain the lack of clinical benefit. Decreased depth-of-focus may be an issue with aspheric IOLs and it remains to be seen whether the corneal spherical aberration should be corrected fully, partially, or neutrally to get the maximum visual benefit.

\section{References}

1 Campbell FW, Gregory AH. Effect of pupil size on visual acuity. Nature 1960; 187: 1121-1123.

2 Güell JL, Pujol J, Arjona M, Diaz-Douton F, Artal P. Optical Quality Analysis System: instrument for objective clinical evaluation of ocular optical quality. J Cataract Refract Surg 2004; 30: 1598-1599.

3 Navarro R, Moreno-Barriuso E. Laser ray-tracing method for optical testing. Opt Lett 1999; 24: 951-953.

4 Guirao A, Gonzalez C, Redondo M, Geraghty E, Norby S, Artal P. Average optical performance of the human eye as a function of age in normal population. Invest Ophthalmol Vis Sci 1999; 40: 203-213.

5 Artal P, Berrio E, Guirao A, Piers P. Contribution of the cornea and internal surfaces to the change of ocular aberrations with age. J Opt Soc Am A 2002; 19: 137-143.

6 McLellan JS, Marcos S, Burns SA. Age-related changes in monochromatic wave aberrations in the human eye. Invest Ophthalmol Vis Sci 2001; 42: 1390-1395.

7 Smith G, Cox M, Calver R, Garner LF. The spherical aberration of the crystalline lens of the human eye. Vision Res 2001; 15: 235-243.

8 van den Berg TJ. Analysis of intraocular straylight, especially in relation to age. Optom Vis Sci 1995; 72: 52-59.

9 Mester U, Dillinger P, Anterist N. Impact of a modified optic design on visual function: clinical comparative study. J Cataract Refract Surg 2003; 29: 652-660.

10 Packer M, Fine IH, Hoffman RS, Piers PA. Improved functional vision with a modified prolate intraocular lens. J Cataract Refract Surg 2004; 30: 986-992.

11 Packer M, Fine IH, Hoffman RS, Piers PA. Prospective randomized trial of an anterior surface modified prolate intraocular lens. J Refract Surg 2002; 18: 692-696.

12 Tzelikis PF, Akaishi L, Trindade FC, Boteon JE. Spherical aberration and contrast sensitivity in eyes implanted with aspheric and spherical intraocular lenses: a comparative study. Am J Ophthalmol 2008; 145(5): 827-833.

13 Pandita D, Raj SM, Vasavada VA, Vasavada VA, Kazi NS, Vasavada AR. Contrast sensitivity and glare disability after implantation of AcrySof IQ Natural aspherical intraocular lens: prospective randomized masked clinical trial. J Cataract Refract Surg 2007; 33: 603-610.

14 Tzelikis PF, Akaishi L, Trindade FC, Boteon JE. Ocular aberrations and contrast sensitivity after cataract surgery with AcrySof IQ intraocular lens implantation Clinical comparative study. J Cataract Refract Surg 2007; 33: 1918-1924.

15 Rocha KM, Soriano ES, Chalita MR, Yamada AC, Bottós K, Bottós J et al. Wavefront analysis contrast sensitivity of aspheric spherical intraocular lenses: a randomized prospective study. Am J Ophthalmol 2006; 142: 750-756.

16 Kershner RM. Retinal image contrast and functional visual performance with aspheric, silicone, and acrylic intraocular lenses: prospective evaluation. J Cataract Refract Surg 2003; 29: 1684-1694.

17 Denoyer A, Le Lez ML, Majzoub S, Pisella PJ. Quality of vision after cataract surgery after Tecnis Z9000 intraocular lens implantation: effect of contrast sensitivity and wavefront aberration improvements on the quality of daily vision. J Cataract Refract Surg 2007; 33(2): 210-216.

18 Barbero S, Marcos S, Jiménez-Alfaro I. Optical aberrations of intraocular lenses measured in vivo and in vitro. J Opt Soc Am A Opt Image Sci Vis 2003; 20: 1841-1851. 
19 Atchison DA. Design of aspheric intraocular lenses. Ophthalmic Physiol Opt 1991; 11: 137-146.

20 Holladay JT, Piers PA, Koranyi G, van der Mooren M, Norrby NE. A new intraocular lens design to reduce spherical aberration of pseudophakic eyes. J Refract Surg 2002; 18: 683-691.

21 Kim SW, Ahn H, Kim EK, Kim T. Comparison of higherorder aberrations in eyes with aspherical or spherical intraocular lenses. Eye 2008; 22: 1493-1498 (this issue).

22 Zeng M, Liu Y, Liu X, Yuan Z, Luo L, Xia Y et al. Aberration and contrast sensitivity comparison of aspherical and monofocal and multifocal intraocular lens eyes. Clin Exp Ophthalmol 2007; 35: 355-360.

23 Caporossi A, Martone G, Casprini F, Rapisarda L. Prospective randomized study of clinical performance of
3 aspheric and 2 spherical intraocular lenses in 250 eyes. J Refract Surg 2007; 23: 639-648.

24 Nanavaty MA, Spalton D, Boyce JF, Saha S, Marshall J. Wavefront aberrations, depth-of-focus and contrast sensitivity in a fellow eye study of an aspheric and spherical intraocular lens. J Cataract Refract Surg (in peer review).

25 Bellucci R, Morselli S, Pucci V. Spherical aberration and coma with an aspherical and a spherical intraocular lens in normal age-matched eyes. J Cataract Refract Surg 2007; 33: 203-209.

26 Nagpal KM, Desai C, Trivedi RH, Vasavada AR. Is pseudophakic astigmatism a desirable goal? Indian J Ophthalmol 2000; 48(3): 213-216. 